\title{
Big Boys Don't Cry: Evaluations of Politicians Across Issue, Gender, and Emotion
}

\author{
Kristyn L. Karl ${ }^{1}$ D $\cdot$ Lindsey Cormack ${ }^{1}$
}

Accepted: 7 June 2021

(C) The Author(s), under exclusive licence to Springer Science+Business Media, LLC, part of Springer Nature 2021

\begin{abstract}
Emotional appeals are powerful motivators of political action. Yet the gender of a politician and the existing stereotypes held by audiences complicate the determination of which type of emotional appeal is best suited for different issue areas. In what ways do politicians' emotional appeals serve to mitigate or exacerbate the impact of gender stereotypes across different policy domains? This research examines when politicians pay penalties or gain rewards for their emotional expressions using a survey experiment on a diverse national sample. We find evidence that women politicians are on equal footing or stand to benefit when expressing masculine emotions while also having greater emotional freedom across policy domains. Men politicians, on the other hand, are significantly punished for not acting "manly" enough in masculine policy domains. Nonetheless, these patterns become complicated by both situational context and partisan expectations. The results provide promise for the future prospects of women politicians while pointing to the continued relevance of gendered stereotypes about emotionality in today's political world.
\end{abstract}

Keywords Gender $\cdot$ Emotion $\cdot$ Stereotype $\cdot$ Political evaluation · Partisanship

\section{Introduction}

Politicians oftentimes use the currency of shared compassion or justified anger to inspire individuals to take action. Citizens understand that not all political contexts demand the same sorts of communication strategies. Some issues are better suited to hopeful rhetoric, some to somber approaches, and others to passionate appeals. Politicians certainly have reason to use different tactics in different settings, yet the gender of a politician and the existing stereotypes held by audiences

\section{Kristyn L. Karl}

kkarl@stevens.edu

1 College of Arts and Letters, Stevens Institute of Technology, 1 Castle Point on Hudson, Hoboken, NJ 07030, USA 
complicate the determination of which type of emotional appeal is best suited for different issue areas. This research explores the relationship between gendered issue domains and gendered stereotypes about emotionality among men and women politicians, highlighting the varied ways in which citizens rely on existing stereotypes when evaluating politicians.

Early research shows that women politicians, compared to men, pay a penalty with respect to their perceived competence when expressing emotion (Huddy \& Terkildsen, 1993) and that women have greater reasons to expect backlash when violating gender norms than men (Aalberg et al., 2007). This is in part because people associate leadership broadly and political leaders specifically with traits that are masculine (Dittmar, 2017; Schneider \& Bos, 2014). Although gendered perceptions of leadership have changed over time, such that many people now incorporate feminine qualities in their views of leaders, perceptions and stereotypes of leadership broadly remain masculine (Koenig et al., 2011; Schneider \& Bos, 2019) and masculinity continues to be valued by voters (Bauer, 2020; Holman et al., 2017).

Recent work by Schneider and Bos (2019) leverages social role theory (SRT) and role congruity theory (RCT) to provide a theoretical framework for understanding how gender roles and expectations shape public opinion. They note, "gender interacts with other politically important identities... [and] the division of people into different roles based on group membership creates stereotypical expectations of a group based on the traits required to fulfill that role" (178). Yet, when it comes to expressions of emotion, citizens' stereotypical expectations of men and women politicians have become increasingly complex. In the case of sadness, Marcus (2010) notes that while public crying is typically "less humiliating for women than for men", male politicians have the "freedom to weep" because their "tears are humanizing" whereas "female politicians, by contrast, still have to hold it in" due to stereotypes about emotionality and the ability to lead. In what ways do politicians' emotional appeals serve to mitigate or exacerbate the impact of gender stereotypes within different policy domains? This research evaluates the degree to which both men and women politicians might gain rewards or pay penalties for expressions of emotion depending on the political context.

Much work in political science has examined the impact of gender on perceptions of politicians; we extend this line of research to address how individuals evaluate emotional expressions of men and women politicians when acting consistent with gender stereotypes (versus counter to them) across issue areas that also cue individuals to think in gendered terms. We expect gender biases to be most clearly brought to bear when politicians work in gender-congruent policy domains. Citizens will have clear expectations for men in defense (i.e. strength, anger) and women in education (i.e. communal, compassion) because these pairings are congruent across gender and policy domain and thus allow social role theory and role congruency to be most clearly relied upon. Alternatively, we expect incongruent gender and policy domain combinations to lead citizens to expect politicians to "meet the demands of the situation." Women politicians working in a masculine policy domain ought to project strength and stereotypically masculine emotions whereas men politicians 
working in a feminine policy domain ought to soften their tone and express stereotypically feminine emotions.

Contrary to popular narratives but consistent with recent research, we find that women politicians are on equal footing or stand to benefit when "talking like a man" in masculine policy domains. Women politicians do not face particularly harsh backlash to breaking traditional gender role expectations. Unlike previous research, we find that men politicians are significantly punished for not acting "manly" enough in masculine policy domains. Men who rely on appeals to compassion on defense policy are penalized, perhaps for failing to live up to standards of traditional masculinity. Thus, men that are "gender deviants" are punished, particularly when powerful proscriptive (i.e. "should not") gender norms are violated (Prentice \& Carranza, 2002). In 2019, the American Psychological Association (APA) issued their first-ever guidelines for the practice of psychology with boys and men, drawing on more than 40 years of research and a key takeaway was "that traditional masculinity-marked by stoicism, competitiveness, dominance and aggression-is, on the whole, harmful" (Pappas, 2019, 35). "When a woman cries at work, she confirms the stereotype of women as emotional, hysterical, unable to perform under pressure. But when a man does it, he is defying the stereotype for men-strong, decisivewhich can damage him even more"; yet context matters and gendered expectations are still evolving as "there are some subjects that are simply too heart-wrenching not to cry about, no matter one's gender” (Bennett, 2020). For example, men politicians from both sides of the political aisle have publicly shed tears over the coronavirus pandemic. Are expressions of sadness for others seen as a demonstration of empathy and grief that fits into a different, acceptable category of feminine emotional expressions by men? Our research shows that men politicians' compassion may be appropriate in some contexts while being a liability in others. In what follows, we review the relevant literature before outlining our hypotheses and evaluating them empirically. Then, we explore the impact of partisan perceptions on these findings, providing preliminary analyses for ongoing theory development that can be explicitly tested in future work. Last, we discuss the results in terms of evolving gender stereotypes and societal norms.

\section{Emotion and Gendered Political Communication}

Gender is a simple and often visible cue that voters use to form expectations about how politicians will act such as inferring feminine traits to women and masculine traits to men (McDermott, 1998; Mo, 2015), especially in low information environments (Feldman \& Conover, 1983). For decades the experimental and observational literatures on voter perceptions of women politicians concluded that women were at a disadvantage to men in the eyes of constituents, even in the most evenly matched circumstances (e.g. Dolan, 2010; Kahn, 1994; Lawless, 2004; Sanbonmatsu, 2002). Women have been perceived as passive, emotional, and caring, while men are generally considered ambitious, competent, and aggressive (Mandel, 1981). Harp et al., (2016) pointedly summarize emotional expectations associated with gender: 
Both anger and sadness play an interesting role in gender boundaries. Shields (2002) highlights that anger has long been linked to masculinity and is associated with action, or at least an impulse to change things. It is a masculine prerogative, an emotion of entitlement. Sadness and crying, on the other hand, are not considered appropriate for men (e.g., "boys don't cry"). As emotions of powerlessness, argues Shields (2002), they are deemed more properly feminine. Breaking such gendered emotion norms (e.g., a very angry woman, a man crying in public) is often met with social sanction (Citrin et al., 2004; Gesualdi, 2013). (Harp et al., 2016, 196)

Combining the influence of emotional expectations and baseline competency prejudices, women leaders have also been perceived as less effective when expressing anger (Lewis, 2000) and are expected to react to negative events with sadness while men are not held to the same expectation (Hess et al., 2000).

Yet voters differentiate stereotypes about "women politicians" from those about "women" or "politicians" as groups (Schneider \& Bos, 2014). Women politicians are a subtype of women and may be subject to different expectations than the broader groups to which they are members; but it is not clear that the same applies to men, as men and masculinity are both associated with politics. Early experimental work on executive speechmaking found that women do not pay penalties for appealing to masculine emotions such as anger if the context is masculine in nature, such as policing and crime (Leeper, 1991). And recent research finds women are not penalized for appearing tougher, and in fact, may benefit above and beyond men for acting tough in some parts of the political world (Brooks, 2013). Therefore, despite early speculation that women politicians may face greater penalties for displaying emotion (Glaser \& Salovey, 1998; Shields \& MacDowell, 1987), Brooks (2011) finds "simply no evidence that women candidates face disproportionate penalties on Election Day if they cry or get angry" (609). Relatedly, Bauer (2017) has found that acting masculine can improve evaluations of women on man-typical traits like experience and knowledge, yet backlash occurs, particularly from opposing partisans, as women can be judged as too tough (Krupnikov \& Bauer, 2014). Thus, men may have more freedom to act in ways that are counter to expectations without fear of blowback (Bauer, 2017).

\section{Issues and Gendered Expectations}

Social norms and stereotypes lead people to think of particular topics or domains as aligning with particular groups who might be better able to handle or address the topic. Psychological research on stereotyping proves instructive regarding reliance on stereotypes; "People will use whatever information they believe is most diagnostic of a judgment" (Crawford et al., 2011, 530). Importantly, people individually determine (consciously or unconsciously) which stereotypes are most diagnostic in any given situation. In what follows, we outline expectations consistent with elements of much of the previously reviewed literature which may help distill some of the discrepant results. 
Our hypotheses focus on the role of emotion in navigating expectations based on policy domain and politician gender. First, gendered expectations ought to most clearly and significantly be brought to bear when there is congruency between a politician's gender and issue domain. Politicians ought to perform better (relative to the opposite gender) when working in a gender congruent policy issue.

\section{H1: Gender Congruent Issue}

H1a: Women politicians will be evaluated more favorably in education than men politicians, holding all else constant.

H1b: Men politicians will be evaluated more favorably in defense than women politicians, holding all else constant.

Consistent with Winter (2010) and Schneider and Bos (2019), this reasoning suggests that stereotypes about gender and policy domains can align in a manner that makes expectancies clear and violations straightforward.

Our overarching theoretical expectation is that gendered issue domain expectations ought to trump gendered emotional appeal expectations. In other words, politicians ought to emotionally meet the demands of the situation, not merely stay in their gendered lane. Why? When politicians work in domains that are congruent with their gender, stereotypes can more clearly be applied, and violations become easier to identify. In political evaluations, people should perceive issue domain stereotypes as more diagnostic for the evaluation at hand than stereotypes about emotional appeals. This is consistent with Brooks (2011) which suggests stereotypes about emotionality exist for ordinary men and women but that political leaders are relatively immune to them as a function of their status. We suggest that politicians are not immune, per se, to stereotypes about emotionality, but rather, more narrowly relevant evaluation metrics may supersede when they can be easily applied. Since the evaluation at hand is political, citizens will rely on policy domain expectations when they can, and emotional appeal expectations when they must.

Therefore, when issue domain and gender align, evaluations can more easily be based on existing attitudes such as partisanship, one of the most narrowly relevant attitudes to a political evaluation. But, when there is incongruence, with issue domain, emotionality, or gender, voters have multiple relevant stereotypes that can be called upon. In such cases, leveraging emotion that is congruent with the issue domain (i.e. meeting the demands of the situation) ought to trump gendered emotional expectations. Women politicians should not be penalized for "trespassing" into masculine domains because men and women politicians alike must work across gendered policy domains and should meet the emotional demands necessary given the context. Plus, women politicians are subcategorized differently than women with respect to emotionality stereotypes and gendered leadership expectancies are evolving, especially among Democratic voters (Bauer, 2019, 2020). Therefore, we expect both men and women politicians can leverage emotional appeals to "meet the demands of the situation" in gender incongruent issue domains.

H2: Meet Demands (Gender Incongruent Issue) 
H2a: Women politicians will not be penalized (in comparison to men) for appeals to anger (masculine emotion) within a masculine issue domain (defense).

$\mathrm{H} 2 \mathrm{~b}$ : Men politicians will not be penalized (in comparison to women) for appeals to sadness (feminine emotion) within a feminine issue domain (education).

Our primary expectation does not preclude emotion from playing a role in evaluations, as citizens ought to punish incongruent emotional appeals when issue domain and gender are congruent. It is in this context where gendered expectations for politicians most clearly come into play. Women politicians can now benefit from their status as a subtype in terms of expressing masculine emotion, whereas men politicians will be constrained by the need for masculinity. As noted previously, while norms around men expressing sadness may be evolving based on the context, we expect the clearest lines will be drawn when men politicians do not live up to expectations for strong leadership and masculine emotionality in a masculine domain such as defense policy.

H3: Emotional Freedom (Gender Congruent Issue)

H3a: Women politicians will not be penalized for appeals to anger (masculine emotion) (in comparison to sadness) within a gender-congruent (feminine) issue domain (education).

H3b: Men politicians will* be penalized for appeals to sadness (feminine emotion) (in comparison to anger) within a gender-congruent (masculine) issue domain (defense).

Consistent with role congruity and expectancy-violation theory (Prentice \& Carranza, 2002), these hypotheses suggest men politicians do not have the same flexibility to leverage feminine emotional appeals because gendered expectations for men politicians continue to be more straightforwardly masculine (unlike the unique stereotypes applied to women politicians).

\section{Methods}

In June 2018, we assessed the impact of gendered emotional appeals on evaluations of men and women politicians when addressing topics that are stereotypically congruent or incongruent with their gender. To do so, we fielded a survey experiment on a nationally diverse online sample of more than 1400 U.S. citizens ages 18 or older from June 14 to 19,2018 . The sample was recruited by Survey Sampling International (SSI) and closely matches U.S. Census benchmarks, though it is not nationally representative. ${ }^{1}$ The median respondent was 45 years old (range 18-97 years) and $53 \%$ identified as women. Racial and ethnic self-identification was $79 \%$ white, $10 \%$

\footnotetext{
1 We opt not to use weights to approximate a national sample since the randomization was effective and the sample characteristics are well-distributed.
} 
black, and 12\% Hispanic. The modal education level was an Associate's degree. Moreover, the sample included respondents from every state and Washington, D.C. and political party affiliations were well-distributed with 40\% Democrats, 39\% Republicans, and $21 \%$ Independents (or "Other"). ${ }^{2}$ Table A1 (appendix) provides the sample properties across key demographic variables.

The study was a between-subjects 2 (Politician Gender: Man, Woman) X 2 (Issue Domain: Education, Defense) X 2 (Emotional Appeal: Sadness, Anger) design. Table A2 (appendix) provides the sample sizes for each treatment condition. We maintain that expressions of sadness and the education policy domain are congruent with femininity and women politicians, whereas expressions of anger and the defense policy domain are congruent with masculinity and men politicians. Respondents began the survey by answering questions about their political attitudes (partisanship, media use, political interest, and policy priorities) before responding to several distractor questions. Then, respondents were told they would "read a randomly chosen online news story" and that we would ask for their feedback.

There were eight treatment conditions, delivered as a newspaper article varying the title and politician image to manipulate politician gender, issue domain, and emotional appeal. The title highlighted the emotional response (sadness or anger) of the politician to a policy issue (education or defense) and each had an image of the politician. For example, "Angry Representative Seeks Defense Reform." The images were official photos of sitting members of Congress. Members were selected that were not party leaders or well-known figures and were pretested on a separate out of sample analysis to ensure comparability across a range of characteristics. ${ }^{3}$ The article briefly explained a fictitious policy failure and then offered a quote from the politician expressing his or her reaction which mirrors the primary emotional manipulation in the headline of each treatment (see Figures A1 - A2, appendix). Following exposure to one article, respondents were asked about their interest in the article and their recollection of the topic (policy issue) before rating the politician on favorability, agreement with the issue response in the article, perceived partisanship, and several qualities (competence, strong leadership, intelligence, compassion, and sincerity). ${ }^{4}$ Lastly, respondents were asked about their political behaviors and demographic questions.

Importantly, there was no explicit mention of the partisanship of the politicians across all conditions. Instead, we asked respondents which party they think the

\footnotetext{
2 To be consistent with national polling, this categorization does not place "Leaners" as partisans. In all* subsequent analyses, we do categorize so-called leaners as partisans based on research showing they behave as partisans (Keith et al., 1986; Magleby \& Nelson, 2012). The breakdown shifts to 45\% Democrats, $9 \%$ Independents or Other, and $46 \%$ Republicans.

3 The pretest sample was fielded in October 2017 on Amazon Mechanical Turk. The sample size was $\mathrm{n}=539$. The man and woman politician were chosen based on statistical comparability across characteristics such as competence, friendliness, intelligence, and trustworthiness, among others.

4 The manipulation check regarding policy issue was correctly identified by $74 \%$ of the sample. All of the primary analyses have been re-run with the $26 \%$ of the sample that incorrectly identified the topic of the article excluded and none of the substantive results (in terms of directionality and significance) change. We opt to keep these respondents in the sample following the best practice established and justified in (Aronow, Baron, \& Pinson, 2019).
} 
politician belongs to after seeing the treatment and responding to questions about politician favorability and evaluations. This design decision means that variations in respondents' perceptions of partisanship are endogenous to the treatment manipulations and are, in part, attributable to the politician's gender, the issue domain, and/or the emotional expression. ${ }^{5}$ As such, our hypotheses and analyses focus primarily on the manipulated variables (emotion, issue domain, and gender). We explore the role of perceptions of partisanship at the end of the paper, as an extension for theoretical development that warrants explicit testing in future work.

\section{Results and Discussion}

We begin by reviewing the main treatment effects on two dependent measures, favorability and issue response. For favorability, respondents were asked "How favorable do you find \{Bill/Mary Flager\}? with a 5-point response scale from "very unfavorable" to "very favorable." For issue response, the question asked, "To what extent do you agree with \{Bill/Mary Flager's \} response on this issue?" with a 5-point response scale from "not at all" to "a lot." As indicated by the question wordings, the favorability item is a broad assessment of overall attitudes toward the politician whereas the issue response item more narrowly addresses respondents' perception of the politician's response to the issue. Table 1 provides the results of simple multivariate models that include several control variables known to influence politician evaluations: respondent partisanship, gender, age, nonwhite status and education level. ${ }^{6}$ The sample is split by issue domain, as holding constant the strongest partisan cue allows for cleaner comparisons of the role of gender and emotion. The treatment variables are included as dummy indicators and their joint effect is included as an interaction term; therefore, for education cue, the change is from defense policy to education policy whereas for anger cue, the change is from the expression of sadness to anger. For ease of interpretation, the marginal effects of the treatment manipulations for favorability are plotted in Fig. 1 and those for issue response are plotted in Fig. 2.

Recall, our first hypothesis, Gender Congruent Issue, expected women to be favored over men in education policy (H1a) and men to be favored over women in defense policy (H2a), holding all else constant. To test our hypotheses, we fix particular values of the treatment conditions based on each hypothesis being tested and allow the observed values to be used for all other variables. This approach evaluates the significance of the average predicted change due to the single isolated treatment variable. For H1, we isolate the marginal effect of shifting from a man politician to a woman politician within each policy domain while pooling

\footnotetext{
${ }^{5}$ Recall, the politician images were pretested across a range of characteristics. As expected based on the literature, the woman politician was perceived as significantly more Democratic $(0.45$ on the $0-1$ scale with Republican high) than the man politician (0.60) when no additional information was given $(\mathrm{p}<0.000)$.

6 The data and replication code for all of the analyses in this paper are available at: https://osf.io/6rfua/
} 
Table 1 Evaluations of favorability and issue response by issue, gender, and emotion

\begin{tabular}{|c|c|c|c|c|}
\hline & \multicolumn{2}{|l|}{ Defense } & \multicolumn{2}{|l|}{ Education } \\
\hline & Favorability & Issue response & Favorability & Issue response \\
\hline \multirow[t]{2}{*}{ Female Politician } & $0.085 * * *$ & $0.083 * * *$ & $0.053 * *$ & $0.056^{*}$ \\
\hline & $(0.025)$ & $(0.029)$ & $(0.025)$ & $(0.029)$ \\
\hline \multirow[t]{2}{*}{ Angry Emotion Cue } & $0.061 * *$ & 0.022 & 0.008 & 0.001 \\
\hline & $(0.025)$ & $(0.029)$ & $(0.026)$ & $(0.029)$ \\
\hline \multirow[t]{2}{*}{ Female Pol. X Angry Cue } & $-0.079 * *$ & $-0.082 * *$ & -0.019 & -0.035 \\
\hline & $(0.035)$ & $(0.040)$ & $(0.036)$ & $(0.041)$ \\
\hline \multirow[t]{2}{*}{ Female Respondent } & -0.022 & $-0.052 * *$ & 0.002 & 0.029 \\
\hline & $(0.018)$ & $(0.021)$ & $(0.019)$ & $(0.021)$ \\
\hline \multirow[t]{2}{*}{ Respondent PID (R) } & $0.064 * * *$ & $0.077 * * *$ & $-0.066 * * *$ & $-0.070 * * *$ \\
\hline & $(0.022)$ & $(0.026)$ & $(0.023)$ & $(0.026)$ \\
\hline \multirow[t]{2}{*}{ Age } & -0.017 & -0.013 & $-0.089 * *$ & $-0.192 * * *$ \\
\hline & $(0.042)$ & $(0.048)$ & $(0.044)$ & $(0.050)$ \\
\hline \multirow[t]{2}{*}{ Nonwhite } & $-0.054 * * *$ & $-0.043^{*}$ & $-0.083 * * *$ & $-0.064 * *$ \\
\hline & $(0.021)$ & $(0.024)$ & $(0.022)$ & $(0.025)$ \\
\hline \multirow[t]{2}{*}{ Education } & $0.090 * *$ & 0.055 & 0.050 & 0.025 \\
\hline & $(0.036)$ & $(0.042)$ & $(0.041)$ & $(0.046)$ \\
\hline \multirow[t]{2}{*}{ Constant } & $0.524 * * *$ & $0.522 * * *$ & $0.680 * * *$ & $0.669 * * *$ \\
\hline & $(0.035)$ & $(0.040)$ & $(0.038)$ & $(0.043)$ \\
\hline Observations & 702 & 703 & 684 & 686 \\
\hline R-squared & 0.062 & 0.052 & 0.039 & 0.041 \\
\hline
\end{tabular}

Standard errors in parentheses. *** $\mathrm{p}<0.01, * * \mathrm{p}<0.05, * \mathrm{p}<0.1$

across emotional appeal. For favorability, the marginal effect of seeing a female politician (versus a man) within the education policy domain is positive and significant $(0.04, \mathrm{p}=0.02)$, consistent with H1a. The effect within the defense policy domain is also positive and significant $(0.05, \mathrm{p}=0.01)$, contrary to H1b (wherein the effect was expected to be negative and significant, which would have indicated significantly greater favorability for a man politician). The results of each hypothesis test are summarized in Table 2.

Our second hypothesis, Meet Demands, suggested that neither women (H2a) nor men $(\mathrm{H} 2 \mathrm{~b})$ politicians would be penalized (relative to the opposite gender) for using emotion to meet the demands of the situation. In other words, when working in an incongruent policy domain (i.e. women in defense or men in education), women would not be penalized for using masculine emotion (anger) and men would not be penalized for using feminine emotion (sadness). The logic of this hypothesis suggests that voters are aware that different domains call for different types of behavior and softening an emotional appeal or toughening up is necessary for both men and women politicians alike.

Looking at Fig. 1, the results within defense policy reveal that angry men and women politicians are evaluated similarly, with no significant difference in 


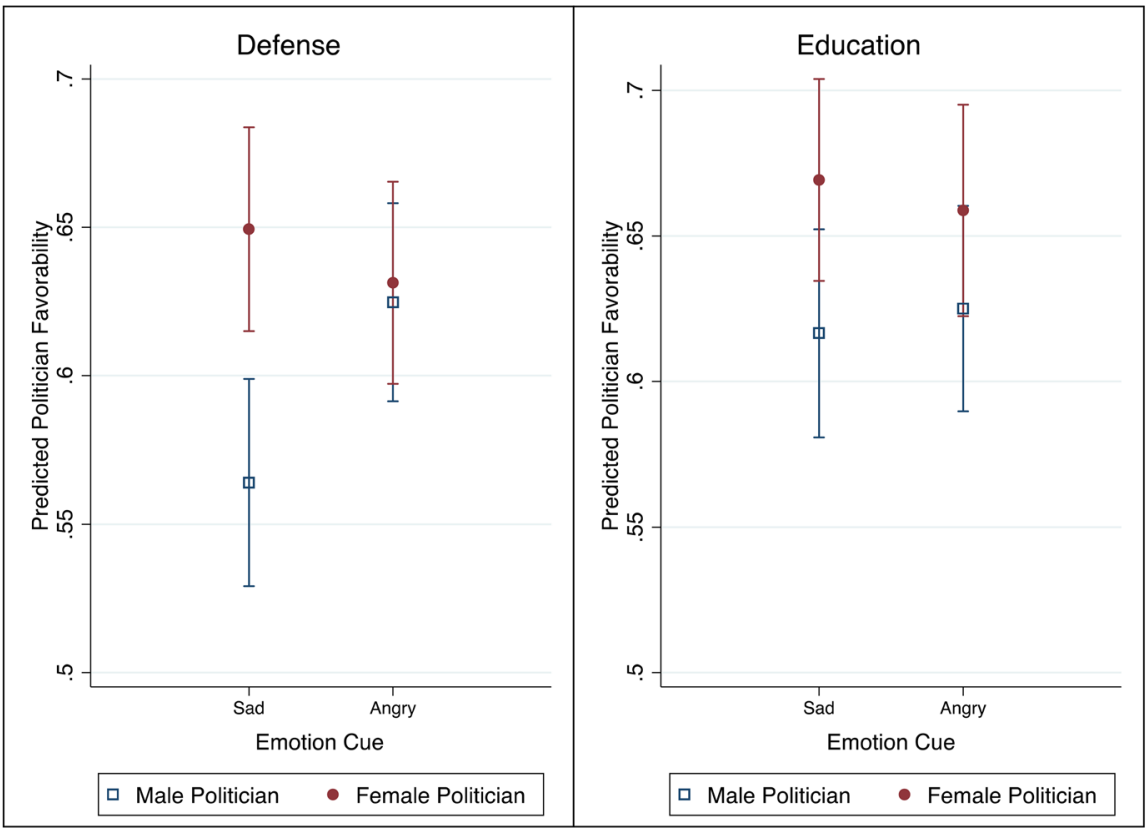

Fig. 1 Politician favorability by politician gender and emotion across issue domain

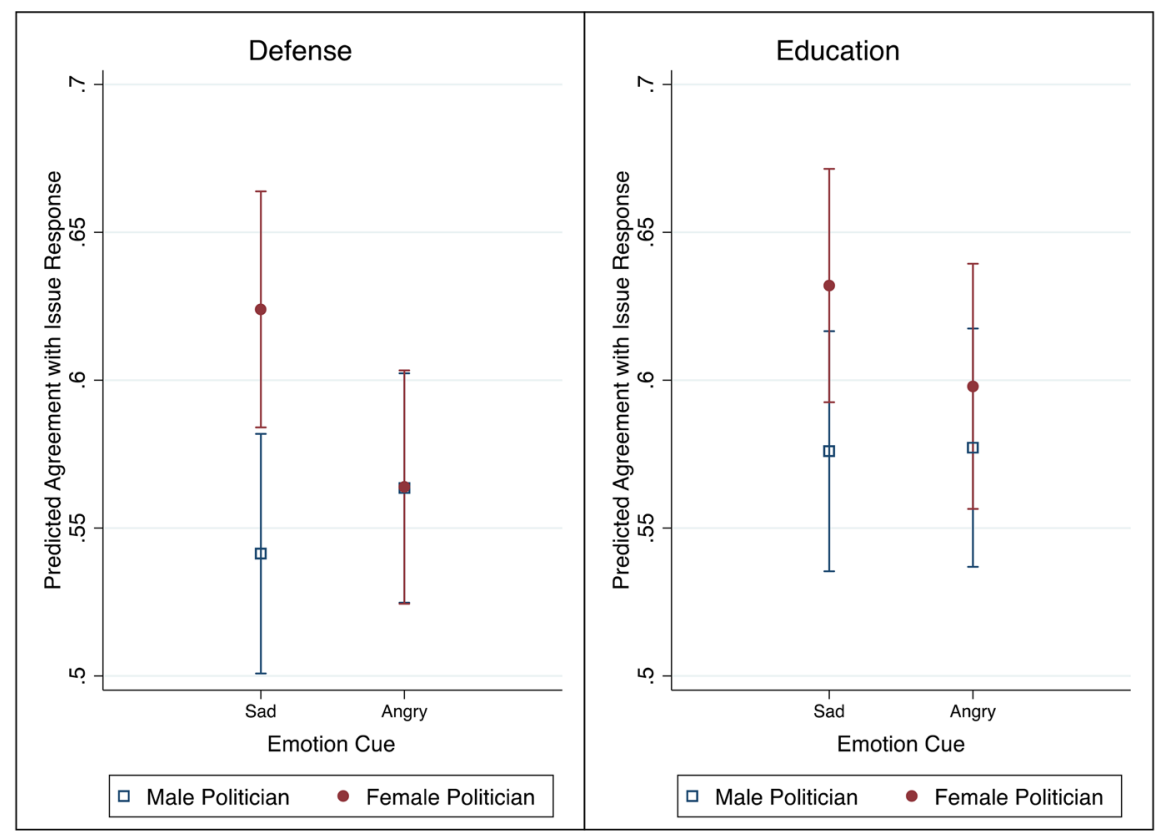

Fig. 2 Agreement with issue response by politician gender and emotion across issue domain 
Table 2 Hypothesis test results

\begin{tabular}{|c|c|c|c|c|}
\hline \multicolumn{2}{|l|}{ Hypothesis } & $\begin{array}{c}\text { Average Marginal } \\
\text { Effect }\end{array}$ & Favorability & $\begin{array}{c}\text { Issue } \\
\text { Response }\end{array}$ \\
\hline \multirow{2}{*}{ Gender Congruent Issue } & H1a & $\begin{array}{l}\text { Within Education: } \\
\text { Change from Man to } \\
\text { Woman Politician }\end{array}$ & $\begin{array}{c}0.04^{* *} \\
(\mathrm{p}=0.02)\end{array}$ & $\begin{array}{c}0.04^{*} \\
(p=0.06)\end{array}$ \\
\hline & $\begin{array}{r}\text { H1b } \\
\times\end{array}$ & $\begin{array}{l}\text { Within Defense: } \\
\text { Change from Man to } \\
\text { Woman Politician }\end{array}$ & $\begin{array}{l}0.05^{* * *} \\
(\mathrm{p}=0.01)\end{array}$ & $\begin{array}{c}0.04^{* *} \\
(\mathrm{p}=0.05)\end{array}$ \\
\hline \multirow{2}{*}{$\begin{array}{c}\text { Meet Demands } \\
\text { (Gender Incongruent Issue) }\end{array}$} & $\begin{array}{l}\mathrm{H} 2 \mathrm{a} \\
\vee\end{array}$ & $\begin{array}{l}\text { Within Defense: } \\
\text { Change from Man to } \\
\text { Woman Politician } \\
\text { (Anger Constant) }\end{array}$ & $\begin{array}{c}0.01 \\
(p=.79)\end{array}$ & $\begin{array}{c}0.000 \\
(p=0.99)\end{array}$ \\
\hline & H2b & $\begin{array}{l}\text { Within Education: } \\
\text { Change from Man to } \\
\text { Woman Politician } \\
\text { (Sadness Constant) }\end{array}$ & $\begin{array}{c}0.05^{* *} \\
(p=0.04)\end{array}$ & $\begin{array}{c}0.06^{* *} \\
(p=0.05)\end{array}$ \\
\hline \multirow{2}{*}{$\begin{array}{c}\text { Emotional Freedom } \\
\text { (Gender Congruent Issue) }\end{array}$} & $\begin{array}{r}\mathrm{H} 3 \mathrm{a} \\
V\end{array}$ & $\begin{array}{l}\text { Within Education: } \\
\text { Change from Sadness to } \\
\text { Anger } \\
\text { (Woman Politician } \\
\text { Constant) }\end{array}$ & $\begin{array}{c}-0.01 \\
(p=0.68)\end{array}$ & $\begin{array}{c}-0.03 \\
(p=0.24)\end{array}$ \\
\hline & $\begin{array}{l}\text { H3b } \\
\times \\
X\end{array}$ & $\begin{array}{c}\text { Within Defense: } \\
\text { Change from Sadness to } \\
\text { Anger } \\
\text { (Man Politician Constant) }\end{array}$ & $\begin{array}{l}0.06 * * * \\
(\mathrm{p}=0.01)\end{array}$ & $\begin{array}{c}0.02 \\
(p=0.44)\end{array}$ \\
\hline
\end{tabular}

Results isolate the average marginal effect associated with each change. Shading indicates consistency with each hypothesis. $* * * \mathrm{p}<0.01, * * \mathrm{p}<0.05, * \mathrm{p}<0.1$

favorability evaluations across gender. This is consistent with $\mathrm{H} 2 \mathrm{a}$, as men behaving congruently masculine (angry in defense policy) are evaluated as similarly favorable to women meeting the demands of the situation by leveraging a masculine emotion in a masculine domain (angry in defense policy). As expected, the marginal effect of shifting from a man politician expressing anger to a female politician expressing anger in the defense domain is not significant $(0.01, p=0.79$, see Table 2). Turning to the results within education policy, women politicians have a slight advantage over men politicians in terms of overall favorability across emotional appeal, as women politicians addressing education policy is congruently feminine (consistent with H1a). Men expressing sadness appear less favorable than women doing so when working in education policy and the marginal effect of moving from a man politician to a woman politician while holding constant the use of sadness in education reveals that women are significantly favored over men $(0.05, \mathrm{p}=0.04$, see Table 2$)$, inconsistent with H2b. Therefore, where a woman can use anger to meet the demands of the situation in the defense domain, it appears men cannot equally leverage sadness to meet the situational need in education.

We turn now to our third hypothesis, Emotional Freedom, which expected that women politicians (but not men) would have greater emotional freedom in gender congruent policy domains. Recall, we expect violations of these gendered emotional 
norms to be most clear when men and women are working in gender congruent policy domains (women in education and men in defense). In this case, the relevant social identities are men politicians and women politicians, which ought to have different stereotypical norms. Women politicians are a subtype of politicians more broadly and therefore have greater emotional freedom to express atypical gendered emotions (i.e. masculine anger); our hypothesis suggests women should not be penalized based on their emotional expression in education policy because they have the emotional freedom to express both anger and sadness (H3a). Men, on the other hand-who represent the norm within politicians - should face stronger gender stereotypes around the expression of sadness and a perceived violation of masculine expectations in a gender-congruent masculine domain (defense policy) should lead to greater social sanction $(\mathrm{H} 3 \mathrm{~b})$.

Looking at education policy in Fig. 1, women politicians are not penalized for expressing an incongruent (masculine) emotion (anger) within a congruently feminine domain (education) (consistent with $\mathrm{H} 3 \mathrm{a}$ ). Unlike the previous examination of marginal effects which isolated the shift from a man politician to a woman politician, this hypothesis test isolates the impact of shifting from expressing sadness to expressing anger while holding constant that the comparison is within women politicians and education policy. Thus, we examine the Emotional Freedom hypothesis by focusing on the shift in overall favorability attributable to the change in emotional expression within a policy domain and politician gender. Consistent with $\mathrm{H} 3 \mathrm{a}$, among women in education, there is no significant difference in favorability when comparing the expression of sadness to the expression of anger $(-0.01, p=0.68$, see Table 2). On the whole, education policy appears to be evaluated based predominantly on gender congruity, as women are perceived to be better equipped to handle the feminine issue of education, regardless of emotional expression.

Turning to emotional freedom among men (H3b), Fig. 1 reveals the clearest distinction in favorability across both issue domains arises when examining the use of sadness in the defense policy domain. Across both panels, the marginal effects of seven of the eight conditions appear statistically indistinguishable, yet the single exception is a significant decrease in favorability for men expressing sadness in the defense issue domain. This penalty in favorability evaluations for men politicians failing to live up to masculine expectations in a congruent policy domain is evidence in support of $\mathrm{H} 3 \mathrm{~b}$. As with the previous hypothesis test, we isolate the marginal effect of shifting from an expression of sadness to an expression of anger among men politicians in the defense domain on favorability; consistent with $\mathrm{H} 3 \mathrm{~b}$, anger significantly increases favorability (or sadness significantly decreases if the coding is reversed) $(0.06, p=0.01$, see Table 2$)$. Thus, women have greater emotional freedom than men when working in gender congruent policy domains.

On agreement with issue response (Table 1 and Fig. 2), many of the above patterns hold true. First, there is little to distinguish men from women in the domain of education policy, though women continue to have a small directional advantage that achieves marginal statistical significance (consistent with H1a). Second, issue agreement scores are lower overall than favorability scores, and this is particularly clear when both men and women are angry in the defense domain as respondents move toward a neutral position (a score of 0.5 ). From our perspective, this result 
reveals the willingness of respondents to distinguish overall favorability from more narrow evaluations of whether they agree with the politicians' response on the issue. Politicians that are angry within the defense domain can be somewhat favorable even as individuals express less agreement with their response to the issue. Notably, the clear favorability penalty among men expressing sadness in the defense domain becomes less clear when evaluations shift to agreement with issue response. Looking elsewhere in Table 1, as respondents more strongly identify as Republicans, they favor politicians working in education significantly less and politicians working in defense significantly more, likely due to expectations regarding partisan issue ownership.

Taken together, the main treatment effects reveal evidence in support of the theory that women politicians are more able than men to leverage role incongruity and meet the demands of the situation through different emotional expressions and to have the emotional freedom in role congruent policy contexts to express emotions not typically perceived as aligned with their gender. There may be "Many Ways to Be a Girl, but One Way to be a Boy"; as popular culture messages aimed at girls have focused on empowerment, younger generations of women report valuing leadership, greater interest in math and science, and increased consideration of running for office whereas boys continue to express pressure to play sports, exhibit strength and toughness, and hide feelings of sadness or fear (Miller, 2018). A PEW survey extends these types of attitudes about gender to partisan differences, finding disagreements among Democrats and Republicans on views about whether gender differences are rooted in biology, the degree to which society values masculinity, and beliefs about gender norms in raising children (Parker et al., 2017). As a final step in this research, we turn now to exploring the influence of perceived partisanship on our findings.

\section{Perceptions of Partisanship}

Academic debate continues over the relative influence of partisanship and gender on evaluations of politicians. Some evidence suggests people rely on partisan stereotypes more so than gender stereotypes (Brooks, 2013; Dolan, 2014) whereas others find gender stereotypes can limit the influence of partisanship (Bauer, 2015, 2019; Holman et al., 2017; Schneider \& Bos, 2016). A third set of findings points to interactive and/or simultaneous impacts of both gender and partisan stereotypes on women politicians specifically (Cassese \& Holman, 2018; Sanbonmatsu \& Dolan, 2009).

Stereotypes about gender and partisanship overlap; Democrats are the "feminine" party and Republicans are the "masculine" party (Hayes, 2011; Winter, 2010). On issue ownership, Republicans are associated with issues such as defense, terrorism, and crime (Egan, 2013; Petrocik, 1996; Petrocik et al., 2003), which are masculine (Huddy \& Terkildsen, 1993; Kahn, 1996), whereas Democrats own the issues of education, healthcare, and the environment, which are feminine. Hayes (2005) evidenced that Democrats are associated with compassion and empathy (feminine 
traits) whereas Republicans are associated with being a strong leader and moral (masculine traits).

The gendered and partisan nature of specific issue domains may activate underlying stereotypes, which could lead citizens to expect specific types of emotional appeals. Thus, Republican anger (masculine) and Democratic compassion (feminine) would be stereotypically congruent on both gendered and partisan terms. When combining gender and partisan biases, role congruity takes on a new dimension, as Republican and Democratic women may not face the same anticipated backlash because their respective voters hold slightly different biases regarding how women should act and what traits are indicative of good leadership (Bauer, 2019).

Without explicit mention of partisanship in this research, respondents' presumptions about partisanship are likely impacted by the treatment manipulations. In this section, we examine the impact of perceptions of partisanship on favorability and issue response. For clarity and transparency, these analyses of differential partisan perceptions should be taken as exploratory and in the interest of theory development that can be tested in future work. Therefore, we do not make and test explicit hypotheses, as the causal agent cannot be disentangled from the treatment manipulations. Nonetheless, a descriptive exploration of how individuals' assessments of partisanship influence our results can prove interesting and enlighten paths for future research.

To capture partisan perceptions, we asked, "When it comes to political partisanship in the United States, how do you suppose \{Bill/Mary Flager\} identifies?" with responses on a 7-point partisan scale from strong Democrat to strong Republican. As anticipated based on the issue ownership literature, perceptions of partisanship were most clearly and significantly impacted by issue domain. A simple linear model predicting projected Republican partisanship based on the treatment conditions reveals issue domain to be highly significant $(\mathrm{p}<0.000)$, as moving from the defense issue domain to the education issue domain and accounts for movement equivalent to approximately one scale point (on the fully labeled seven-point partisanship scale). On average, politicians addressing defense policy were thought to lean Republican whereas those working in education were thought to lean Democratic (see Fig. 3). Politician gender had a much smaller yet significant impact (about one-fourth of a scale point), such that women politicians are perceived as slightly more Democratic than men $(\mathrm{p}=0.05)$. Emotional cues did not impact perceived partisanship.

Table 3 presents the results of similar multivariate regression models as the original analyses. However, the models now include an interaction between the treatment condition and respondents' perception of the politician's partisanship. This model specification allows the impact of politician gender and emotional appeal on favorability to be dependent on respondents' perceptions of partisanship. Theoretically, citizens might expect different types of emotional appeals based on (what they believe to be) the partisanship of the politician, the politician's gender, and the issue domain in which they are working.

In the education domain, the results are largely similar to what they were prior to including respondent perceptions of partisanship: women politicians continue to be significantly favored over men politicians. Perceptions of partisanship do not seem to influence favorability or agreement with the issue response, yet respondent 


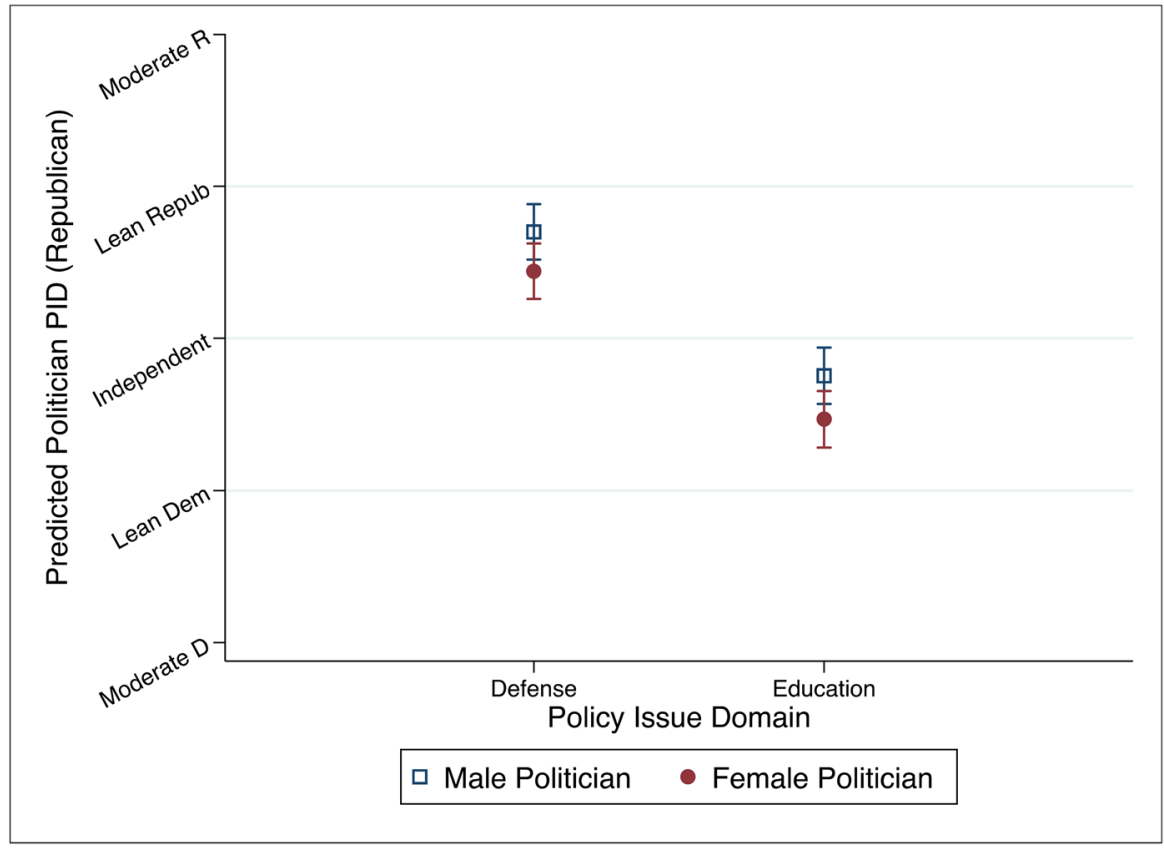

Fig. 3 Perceived partisanship by politician gender and issue domain

partisanship retains its significance, indicating that as respondents identify as increasingly Republican, they evaluate politicians addressing education as significantly less favorable and agreement with their response to the issue significantly decreases. On the whole, including perceptions of politician partisanship in the model does not substantively alter the previous findings: women continue to be evaluated as better equipped to handle the feminine issue of education, regardless of emotional expression and citizens rely heavily on their own partisan identity to infer favorability and agreement based on partisan issue ownership.

Turning to the defense domain, the results are more complicated, as evaluations are dependent on partisan perceptions such that the interaction term is statistically significant and negative. The coefficients on perceived politician partisanship indicate evaluations of men politicians that are sad-when both treatment indicators are at their base level-significantly decline as they are perceived as increasingly Republican. For ease of interpretation, we have isolated the average marginal effect of shifting from sadness to anger in the defense issue domain across treatment conditions (Fig. 4). When looking at Fig. 4, each data point should be interpreted as the penalty (or reward) for the politician's movement from sadness to anger; any value wherein the confidence interval falls clearly above or below the reference line (at zero) is statistically significant at $\mathrm{p}<0.05$. For both dependent measures (favorability and agreement with issue response), the pattern is similar: women politicians are significantly penalized whereas men politicians are significantly rewarded for expressions of anger as they are perceived to be increasingly Republican. Since 
Table 3 Impact of perceived partisanship on evaluations of favorability and issue response

\begin{tabular}{|c|c|c|c|c|}
\hline & \multicolumn{2}{|l|}{ Defense } & \multicolumn{2}{|l|}{ Education } \\
\hline & Favorability & Issue resp. & Favorability & Issue resp. \\
\hline Female Politician & $\begin{array}{l}-0.086 \\
(0.057)\end{array}$ & $\begin{array}{l}-0.104 \\
(0.065)\end{array}$ & $\begin{array}{l}0.083 * \\
(0.046)\end{array}$ & $\begin{array}{l}0.048 \\
(0.052)\end{array}$ \\
\hline Angry Emotion Cue & $\begin{array}{l}-0.047 \\
(0.057)\end{array}$ & $\begin{array}{l}-0.141 * * \\
(0.066)\end{array}$ & $\begin{array}{l}0.056 \\
(0.048)\end{array}$ & $\begin{array}{l}0.037 \\
(0.055)\end{array}$ \\
\hline Female Pol. X Angry Cue & $\begin{array}{l}0.118 \\
(0.078)\end{array}$ & $\begin{array}{l}0.159 * \\
(0.090)\end{array}$ & $\begin{array}{l}-0.104 \\
(0.066)\end{array}$ & $\begin{array}{l}-0.096 \\
(0.075)\end{array}$ \\
\hline Perceived Politician PID (R) & $\begin{array}{l}-0.257 * * * \\
(0.060)\end{array}$ & $\begin{array}{l}-0.330 * * * \\
(0.069)\end{array}$ & $\begin{array}{l}-0.027 \\
(0.063)\end{array}$ & $\begin{array}{l}-0.045 \\
(0.071)\end{array}$ \\
\hline Female Politician X Pol. PID (R) & $\begin{array}{l}0.270 * * * \\
(0.083)\end{array}$ & $\begin{array}{l}0.288 * * * \\
(0.096)\end{array}$ & $\begin{array}{l}-0.073 \\
(0.086)\end{array}$ & $\begin{array}{l}0.014 \\
(0.098)\end{array}$ \\
\hline Angry Cue X Pol. PID (R) & $\begin{array}{l}0.166^{* *} \\
(0.082)\end{array}$ & $\begin{array}{l}0.253 * * * \\
(0.095)\end{array}$ & $\begin{array}{l}-0.100 \\
(0.087)\end{array}$ & $\begin{array}{l}-0.074 \\
(0.099)\end{array}$ \\
\hline $\begin{array}{l}\text { Female Pol. X Angry Cue X } \\
\text { Pol. PID (R) }\end{array}$ & $\begin{array}{l}-0.322^{* * * *} \\
(0.115)\end{array}$ & $\begin{array}{l}-0.387^{* * * *} \\
(0.133)\end{array}$ & $\begin{array}{l}0.191 \\
(0.123)\end{array}$ & $\begin{array}{l}0.130 \\
(0.140)\end{array}$ \\
\hline Female Respondent & $\begin{array}{l}-0.024 \\
(0.018)\end{array}$ & $\begin{array}{l}-0.052^{* *} \\
(0.021)\end{array}$ & $\begin{array}{l}0.003 \\
(0.019)\end{array}$ & $\begin{array}{l}0.028 \\
(0.021)\end{array}$ \\
\hline Respondent PID (R) & $\begin{array}{l}0.086 * * * \\
(0.023)\end{array}$ & $\begin{array}{l}0.106 * * * \\
(0.027)\end{array}$ & $\begin{array}{l}-0.053^{* *} \\
(0.024)\end{array}$ & $\begin{array}{l}-0.065^{* *} \\
(0.028)\end{array}$ \\
\hline Age & $\begin{array}{l}0.000 \\
(0.041)\end{array}$ & $\begin{array}{l}0.007 \\
(0.047)\end{array}$ & $\begin{array}{l}-0.104 * * \\
(0.044)\end{array}$ & $\begin{array}{l}-0.206^{* * * *} \\
(0.050)\end{array}$ \\
\hline Nonwhite & $\begin{array}{l}-0.052^{* *} \\
(0.020)\end{array}$ & $\begin{array}{l}-0.043^{*} \\
(0.024)\end{array}$ & $\begin{array}{l}-0.084 * * * \\
(0.022)\end{array}$ & $\begin{array}{l}-0.066^{* * * *} \\
(0.026)\end{array}$ \\
\hline Education & $\begin{array}{l}0.097 * * * \\
(0.036)\end{array}$ & $\begin{array}{l}0.061 \\
(0.042)\end{array}$ & $\begin{array}{l}0.042 \\
(0.041)\end{array}$ & $\begin{array}{l}0.022 \\
(0.046)\end{array}$ \\
\hline Constant & $\begin{array}{l}0.669 * * * \\
(0.051)\end{array}$ & $\begin{array}{l}0.709 * * * \\
(0.059)\end{array}$ & $\begin{array}{l}0.694 * * * \\
(0.047)\end{array}$ & $\begin{array}{l}0.694 * * * \\
(0.053)\end{array}$ \\
\hline Observations & 700 & 702 & 683 & 685 \\
\hline R-squared & 0.097 & 0.092 & 0.049 & 0.047 \\
\hline
\end{tabular}

Standard errors in parentheses. $* * * \mathrm{p}<0.01, * * \mathrm{p}<0.05, * \mathrm{p}<0.1$

the expression of anger is a dummy variable, the logic could also be stated as the reverse: women politicians are significantly rewarded whereas men politicians are significantly penalized for expressions of sadness as they are perceived to be increasingly Republican. While the exact mechanism (penalizing men's sadness and/ or penalizing women's anger) cannot be distinguished with this data, both interpretations are consistent with role congruity theory. Democratic politicians of both genders may have greater freedom to leverage emotional appeals whereas Republican politicians are expected to conform to traditional gender roles whereby men can be angry but not sad and women can be sad but not angry. 


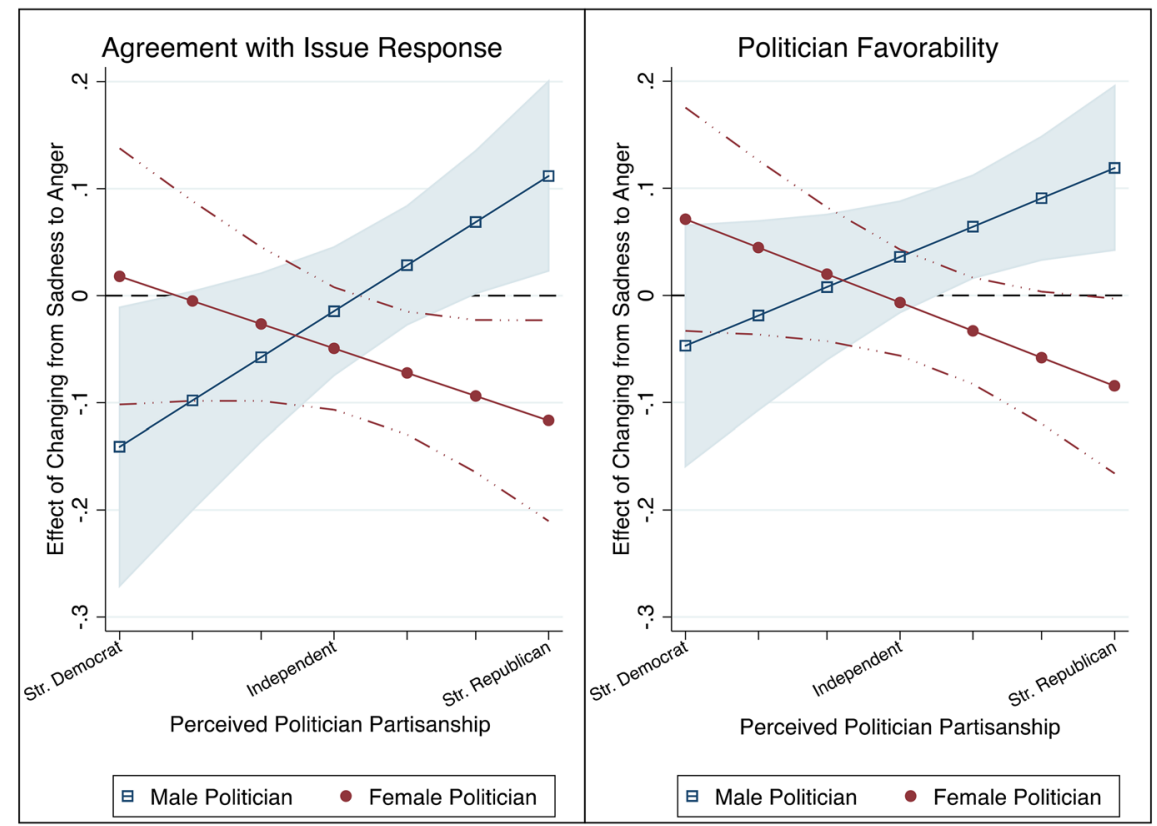

Fig. 4 Marginal effect of expressing anger (versus sadness) in defense issue domain by politician gender and perceived partisanship

Lastly, these models consistently highlight the relevance of respondent partisanship. Whether a respondent is a Republican or a Democrat has a strong and significant influence on the degree to which they favor and support a particular politician's response based largely on whether the issue domain they address aligns with their own partisan identity. This is not surprising and consistent with existing research regarding low-information environments and presumptions of partisan identities. Nonetheless, these exploratory analyses suggest that Republican politicians may be held to different standards of emotional expression than Democratic politicians and the gender of the politician impacts these expectations in predictable ways. When limited to the defense issue domain (a Republican/masculine domain), Democratic men and women appear to have more freedom to leverage a fuller range of emotional expression, whereas Republican politicians appear more constrained by traditional gender role expectations.

When incorporating perceptions of partisanship, our results continue to suggest that women politicians are evaluated as equally or more favorable than men politicians across issue domain and emotional appeals. Thus, meeting the demands of the situation remains valuable. Yet what initially appeared to be greater freedom among women politicians to leverage different types of emotional appeals may be more nuanced when accounting for perceptions of politician partisanship and future research should continue to explore these complexities. Do Democratic politicians have greater freedom to appeal to different emotions without fear of facing backlash, particularly in the defense policy domain (as suggested here)? Alternatively, are 
both Republican men and Republican women politicians more constrained by role congruity that aligns with traditional gender norms for emotional expression? These possibilities are consistent with recent work showing differential partisan leadership expectancies with liberals valuing compassion and conservatives valuing toughness (Clifford, 2020). Our research indicates that perceptions of politician partisanshipeven when inferred based largely on issue domain-may have an outsized influence on overall favorability evaluations and may serve to exacerbate the impact of role congruity by establishing the clearest penalties (and/or benefits) for Republican men politicians working in Republican/masculine issue domains.

\section{Conclusion}

A long thread of research in emotion and politics has made it clear that discrete emotions such as fear, anger, and enthusiasm can have powerful political impacts (see Brader \& Marcus, 2013 for a review). In what ways do politicians gain reward or receive penalties for their emotional expressions? Few studies have examined the joint influence of politician gender, issue domain, and emotional expression on evaluations. We expected issue domain congruency to be a powerful schema for political evaluations, enabling evolving gender stereotypes to be brought to bear on politician evaluations. In recent years it seems that people still believe politics to be masculine but have updated ideas about how women can exist and work in politics. Our results echo this line of research and show that women are less frequently penalized when they violate gender norms for emotionality in politics because it seems that people understand that the arena demands actions that are sometimes at odds with feminine stereotypes. The findings about women's ability to avoid penalties for expressing masculine emotion challenges a body of literature that suggests gender-emotion stereotypes present fundamental barriers to women's ability to effectively lead, particularly when those emotional displays are overtly masculine (Brescoll, 2016; Brescoll \& Uhlmann, 2008). This may be good news for women entering politics, but it does not mean that gender biases no longer permeate and influence voter perceptions.

Work by McDermott (2016) indicates that men and women that subscribe to traditional gender believe men to be suited to politics, in part due to their superior emotional ability. "Politics is a system of gendered institutions and norms where masculinity reigns, particularly in the Republican Party" (Schneider \& Bos, 2019, 186). This work expands upon these results to suggest that citizens do not need to subscribe to traditional roles to evaluate politicians based on the association between Republicanism and traditional gender roles. In other words, assuming a politician is a Republican (or being told so) may activate a set of assumptions about traditional gender roles and the appropriateness of particular types of emotional appeals based on that politician's gender. We present suggestive evidence that Democratic women can be sad or angry without penalty when addressing a masculine issue, yet Republican politicians may not be afforded the same sort of flexibility. On defense policy, men who expressed sadness were penalized the most, arguably due to the penalty faced by Republican men specifically. On the feminine issue of education, women were still favored overall with emotionality having little impact. Future research 
should aim to replicate both sets of results and more directly test the Republican partisan expectations that align emotionality with traditional gender roles.

Our research also illuminates the ways in which context matters, as gendered expectations for emotionality in politics continues to evolve. Women politicians appear to have greater emotional freedom than men, likely due in part to their subtyping and changing norms around women's emotional expressions - whereas men's expressions of sadness or compassion might be appropriate in some contexts but not others. Research focusing on John Boehner, a prominent Republican politician who was widely recognized for his tearful reactions, echoes these masculine expectancies. "His public crying violates norms of masculinity... [and] because of Boehner's political role, he defies traditional masculine performance of political leaders in America" (Gesualdi, 2013, 305). Revealingly, however, Boehner's tears often arose around times of concern for others or situations that warranted compassion: when listening to Pope Francis during his first visit to United States, when presiding over Representative Gabby Giffords' resignation after a targeted gun attack, when accepting the Speaker's gavel in 2011, and when discussing hard work and gratitude at a commencement address (Durando, 2015). As such, men's recent expressions of sadness regarding the coronavirus pandemic may be similarly acceptable. In this research, men's expressions of sadness in a masculine domain are the most steeply penalized-though questions remain about differential partisan expectations based on traditional gender norms. On the whole, this work draws attention to the complexities of emotional expression that remain relevant across politician gender and partisanship.

Our research has several noteworthy limitations. First, we address perceptions of white politicians across two issues domains. As the set of our elected officials becomes more diverse, and with the knowledge that gender and race stereotypes can come together in different and cross-cutting ways (Harris-Perry, 2011), it is imperative that we understand how these perceptions and assessments unfold. Second, analyses of other issue areas, that are less readily identified as masculine or feminine (e.g. mail delivery or veterans care) will also help to better describe the sorts of strategic communication methods best suited to different topics across different politicians. Third, the timing of our research put us in the field ahead of the 2018 midterm elections. Donald Trump's 2016 Presidential campaign was marked by masculine dominance and aggression and the 2018 midterms saw a large increase in women candidates, as the cultural zeitgeist surrounded the \#metoo movement. Therefore, we believe the political environment during this period influenced our findings in ways beyond our control. Attitudes about women were front and center throughout this period and the results of the 2018 midterm elections bear this out, a record number of women were elected. Despite this, we'd expect that the findings with respect to men's emotional displays in masculine policy domains will hold up outside this period. Nonetheless, we also anticipate that some of the findings with respect to the overall favorability of women will weaken over time and plays out differently when not in an experimental context that is subject to social desirability. Overall, we think the trend of research in this domain provides promise for the future prospects of women politicians and the waning relevance of gendered stereotypes regarding emotionality. 
Supplementary Information The online version contains supplementary material available at https://doi. org/10.1007/s11109-021-09727-5.

Acknowledgements We are indebted to Nichole Bauer, Kim Fridkin, several anonymous reviewers, and participants of the conference within the conference on Gender in Political Psychology at the 2019 Annual Meeting of the International Society of Political Psychology (ISPP).

Funding This project was funded through the College of Arts and Letters' Faculty Small Grant program at Stevens Institute of Technology.

\section{References}

Aalberg, T., Todal, J., \& A. (2007). Gender stereotyping of political candidates an experimental study of political communication. Nordicom Review, 28(1), 17-32.

Aronow, P. M., Baron, J., \& Pinson, L. (2019). A note on dropping experimental subjects who fail a manipulation check. Political Analysis, 27(4), 572-589.

Bauer, N. M. (2015). Who stereotypes female candidates? Identifying individual differences in feminine stereotype reliance. Politics, Groups, and Identities, 3(1), 94-110.

Bauer, N. M. (2017). The effects of counter-stereotypic gender strategies on candidate evaluations. Political Psychology, 38(2), 279-295.

Bauer, N. M. (2019). The effects of partisan trespassing strategies across candidate sex. Political Behavior, 41(4), 897-915.

Bauer, N. M. (2020). The qualification gap: Why women must be more qualified than men to win political office. Cambridge University Press.

Bennett, J. (2020). Leaders Are Crying on the Job. Maybe That's a Good Thing (p. A17). NY: The New York Times.

Brader, T., \& Marcus, G. E. (2013). Emotion and Political Psychology. The Oxford Handbook of Political Psychology (2nd ed., pp. 165-204).

Brescoll, V. L. (2016). Leading with their hearts? How gender stereotypes of emotion lead to biased evaluations of female leaders. The Leadership Quarterly, 27(3), 415-428.

Brescoll, V. L., \& Uhlmann, E. L. (2008). Can an angry woman get ahead? Status conferral, gender, and expression of emotion in the workplace. Psychological Science, 19(3), 268-275.

Brooks, D. J. (2011). Testing the double standard for candidate emotionality: Voter reactions to the tears and anger of male and female politicians. Journal of Politics, 73, 597-615.

Brooks, D. J. (2013). He runs, she runs: Why gender stereotypes do not harm women candidates. Princeton University Press.

Cassese, E. C., \& Holman, M. R. (2018). Party and gender stereotypes in campaign attacks. Political Behavior, 40(3), 785-807.

Citrin, L. C., Roberts, T.-A., \& Frederickson, B. L. (2004). Objectification theory and emotions: A feminist psychological perspective on gendered affect. In L. Z. Tiedens \& C. W. Leach (Eds.), The social life of emotions (pp. 203-223). Cambridge: Cambridge University Press.

Clifford, S. (2020). Compassionate democrats and tough republicans: How ideology shapes partisan stereotypes. Political Behavior, 42(4), 1269-1293.

Feldman, S., \& Conover, P. J. (1983). Candidates, issues and voters: The role of inference in political perception. The Journal of Politics, 45(4), 810-839.

Crawford, J. T., Jussim, L., Madon, S., Cain, T. R., \& Stevens, S. T. (2011). The use of stereotypes and individuating information in political person perception. Personality and Social Psychology Bulletin, 37(4), 529-542.

Dittmar, K. (2017). Finding gender in election 2016: Lessons from presidential gender watch (pp. 1-40). Center for American Women and Politics, Rutgers University. Retrieved from http://presidentialgen derwatch.org/report/.

Dolan, K. (2014). When does gender matter? Women candidates \& gender stereotypes in American elections. Oxford University Press.

Dolan, K. (2010). The impact of gender stereotyped evaluations on support for women candidates. Political Behavior, 32(1), 69-88. 
Durando, J. (2015, Sept. 25). Tears through the years: John Boehner gets emotional. USA Today. Retrieved from: https://www.usatoday.com/story/news/nation-now/2015/09/25/john-boehner-crying-emotional-speaker-house/72799814/

Egan, P. J. (2013). Partisan priorities: How issue ownership drives and distorts American politics. Cambridge University Press.

Gesualdi, M. (2013). Man tears and masculinities: News coverage of John Boehner's tearful episodes. Journal of Communication Inquiry, 37, 304-321.

Glaser, J., \& Salovey, P. (1998). Affect in Electoral Politics. Personality and Social Psychology Review, 2(3), 156-172.

Harp, D., Loke, J., \& Bachmann, I. (2016). Hillary Clinton's Benghazi hearing coverage: Political competence, authenticity, and the persistence of the double bind. Women's Studies in Communication, 39(2), 193-210.

Harris-Perry, M. V. (2011). Sister citizen: Shame, stereotypes, and Black women in America. Yale University Press.

Hayes, D. (2005). Candidate qualities through a partisan lens: A theory of trait ownership. American Journal of Political Science, 49(4), 908-923.

Hayes, D. (2011). When gender and party collide: Stereotyping in candidate trait attribution. Politics and Gender, 7(2), 133-165.

Hess, U., Senecal, S., Kirouac, G., Herrera, P., Philippot, P., \& Kleck, R. E. (2000). Emotional expressivity in men and women: Stereotypes and self-perceptions. Cognition \& Emotion, 14(5), 609-642.

Holman, M. R., Merolla, J., \& Zechmeister, E. (2017). Can experience overcome stereotypes in times of terror threat? Research and Politics, 2017, 1-7.

Huddy, L., \& Terkildsen, N. (1993). Gender stereotypes and the perception of male and female candidates. American Journal of Political Science, 37(1), 119-147.

Kahn, K. F. (1994). Does gender make a difference? an experimental examination of sex stereotypes and press patterns in statewide campaigns. American Journal of Political Science, 38(1), 162-195.

Kahn, K. F. (1996). The political consequences of being a woman: How stereotypes influence the conduct and consequences of political campaigns. Columbia University Press.

Keith, B. E., Magleby, D. B., Nelson, C. J., Orr, E., Westlye, M. C., \& Wolfinger, R. E. (1986). The partisan affinities of independent 'leaners.' British Journal of Political Science, 16(2), 155-185.

Koenig, A. M., Eagly, A. H., Mitchell, A. A., \& Ristikari, T. (2011). Are leader stereotypes masculine? A meta-analysis of three research paradigms. Psychological Bulletin, 137(4), 616-642.

Krupnikov, Y., \& Bauer, N. M. (2014). The relationship between campaign negativity, gender and campaign context. Political Behavior, 36(1), 167-188.

Lawless, J. L. (2004). Women, War, and Winning Elections: Gender Stereotyping in the Post-September 11th Era. Political Research Quarterly, 57(3), 479-490.

Leeper, M. S. (1991). The Impact of Prejudice on Female Candidates: An Experimental Look at Voter Inference. American Politics Quarterly, 19(2), 248-261.

Lewis, K. M. (2000). When leaders display emotion: How followers respond to negative emotional expression of male and female leaders. Journal of Organizational Behavior, 21(2), 221-234.

Magleby, D. B., \& Nelson, C. (2012). Independent leaners as policy partisans: An examination of party identification and policy views. The Forum, 10(3), https://doi.org/10.1515/1540-8884.1522.

Mandel, R. (1981). In the running: The new woman candidate. Ticknor \& Fields.

Marcus, R. (2010, Dec. 15). Cry, boehner, cry. The Washington Post, p. A21.

McDermott, M. (1998). Race and gender cues in low-information elections. Political Research Quarterly, 51(4), 895-918.

McDermott, M. (2016). Masculinity, femininity, and American political behavior. Oxford University Press.

Miller, C. (2018). Many ways to be a girl, but one way to be a boy: the new gender rules (p. A9). NY: The New York Times.

Mo, C. H. (2015). The consequences of explicit and implicit gender attitudes and candidate quality in the calculations of voters. Political Behavior, 37(2), 357-395.

Pappas, S. (2019). APA issues first-ever guidelines for practice with men and boys. Monitor on Psychology, 50(1), 34-51.

Parker, K., Horowitz, J.M., \& Stepler, R. (2017, Dec. 5). On gender differences, no consensus on nature vs. nurture. Pew Research Center. Retrieved from: https://www.pewresearch.org/social-trends/2017/ 12/05/on-gender-differences-no-consensus-on-nature-vs-nurture/. 
Petrocik, J. R. (1996). Issue Ownership in Presidential Elections, with a 1980 Case Study. American Journal of Political Science, 40(3), 825-250.

Petrocik, J. R., Benoit, W. L., \& Hansen, G. J. (2003). Issue Ownership and Presidential Campaigning, 1952-2000. Political Science Quarterly, 118(4), 599-626.

Prentice, D. A., \& Carranza, E. (2002). What women and men should be, shouldn't be, are allowed to be, and don't have to be: The Contents of prescriptive gender stereotypes. Psychology of Women Quarterly, 26(4), 269-281.

Sanbonmatsu, K. (2002). Gender Stereotypes and Vote Choice. American Journal of Political Science, 46(1), 20-34.

Sanbonmatsu, K., \& Dolan, K. (2009). Do gender stereotypes transcend party? Political Research Quarterly, 62(3), 485-494.

Schneider, M. C., \& Bos, A. L. (2014). Measuring stereotypes of female politicians. Political Psychology, 35(2), 245-266.

Schneider, M. C., \& Bos, A. L. (2016). The intersection of party and gender stereotypes in evaluating political candidates. Journal of Women, Politics \& Policy, 37(3), 274-294.

Schneider, M. C., \& Bos, A. L. (2019). The application of social role theory to the study of gender in politics. Political Psychology, 40, 173-213.

Shields, S. A., \& MacDowell, K. A. (1987). "Appropriate” Emotion in Politics: Judgments of a Televised Debate. Journal of Communication, 37(2), 78-89.

Shields, S. A. (2002). Speaking from the heart: Gender and the social meaning of emotion. Cambridge University Press.

Winter, N. J. (2010). Masculine republicans and feminine democrats: Gender and Americans' explicit and implicit images of the political parties. Political Behavior, 32(4), 587-618.

Publisher's Note Springer Nature remains neutral with regard to jurisdictional claims in published maps and institutional affiliations. 